\title{
Prospective study of incidence and predictors of peripheral intravenous catheter-induced complications
}

This article was published in the following Dove Press journal:

Therapeutics and Clinical Risk Management

8 December 2014

Number of times this article has been viewed

\author{
Mostafa A Abolfotouh ${ }^{1,2}$ \\ Mahmoud Salam' \\ Ala'a Bani-Mustafa' \\ David White ${ }^{3}$ \\ Hanan H Balkhy 2,4
}

'King Abdullah International Medical Research Center (KAIMRC), ${ }^{2}$ King Saud bin-Abdulaziz University for Health Sciences (KSAU-HS), ${ }^{3}$ Nursing Department, ${ }^{4}$ Infection Prevention and Control Department, King Abdulaziz Medical City, Riyadh, Saudi Arabia
Correspondence: Mostafa A Abolfotouh King Abdullah International Medical Research Center (KAIMRC) (Mail Code 1515), King Saud bin-Abdulaziz University for Health Sciences (KSAU-HS), King Abdulaziz Medical City, National Guard Health Affairs, PO Box 22490, Riyadh I I426, Saudi Arabia Email mabolfotouh@gmail.com
Background: Although intravenous therapy is one of the most commonly performed procedures in hospitalized patients, it remains susceptible to infectious and noninfectious complications. Previous studies investigated peripheral intravenous catheter (PIVC) complications mainly in pediatrics, but apparently none were investigated among Saudi adult populations. The aim of this study was to assess the pattern and complications of PIVCs at King Abdulaziz Medical City (KAMC), Riyadh, Saudi Arabia.

Methods: An observational prospective cohort study investigated PIVCs pattern and complications among adults with PIVCs, admitted to various wards at KAMC. PIVCs-related clinical outcomes (pain, phlebitis, leaking, and others) were recorded in 12-hour intervals, using the Visual Inspection Phlebitis scale. Density incidence (DI) and cumulative incidence (CI) of complications and their relative risks (RRs) were calculated. Regression analyses were applied and significance limits were set at $P<0.05$.

Results: During the study period, 359 adults were included, mounting to 842 PIVCs and 2,505 catheter days. The majority of patients, 276 (76.9\%), had medical, chief admission complaints, whereas $83(23.1 \%)$ were trauma/surgical and infectious cases. Complicated catheters were found in 141 (39.3\%) patients, with 273 complications (32.4/100 catheters), in 190 complicated catheters $(\mathrm{CI}=22.56 / 100$ catheters and $\mathrm{DI}=75.84 / 1,000$ catheter days $)$. Phlebitis ranked first among complications, $148(\mathrm{CI}=17.6 \%)$, followed by pain $64(\mathrm{CI}=7.6 \%)$, leaking $33(\mathrm{CI}=3.9 \%)$, dislodgement 20 ( $\mathrm{CI}=2.4 \%)$, and extravasations and occlusion $4(\mathrm{CI}=0.5 \%$ each). Phlebitis was predicted with female sex $(P<0.001)$, insertion in fore/upper arm $(P=0.024)$, and infusion of medication $(P=0.02)$. Removal time for PIVCs insertion was not a significant predictor of phlebitis (RR $=1.46, P=0.08)$.

Conclusion: Incidence of complications in this study was significantly higher than rates in previous studies. Better insertion techniques may be sought to lower the incidences of PIVC complications, thus extending their onset beyond day 3. Changing catheters is recommended when clinically indicated rather than routinely post-72 hours.

Keywords: catheter-induced complications, peripheral venous catheter, phlebitis, thrombophlebitis, incidence, prospective study

\section{Introduction}

Being one of the most commonly performed procedures on hospitalized patients, peripheral intravenous catheter (PIVC) insertions make them susceptible to infectious and noninfectious complications. ${ }^{1}$ PIVC complications are classified into minor and major categories based on the severity of symptoms. Minor complications include catheter occlusions, accidental removals, fear of sharp catheters (needle phobia), and pain. On the other hand, major complications tend to be more severe, 
such as phlebitis, infection, extravasation, and even skin injuries. ${ }^{2}$ Published studies conducted on PIVCs among adults ranged from randomized controlled trials to descriptive and correlational designs. ${ }^{3-6}$ One systematic review showed incidence of infection to be $0.1-0.2 / 100$ catheters or $0.2-0.9 / 1,000$ catheter days. ${ }^{3}$ Others revealed incidence of phlebitis to be $6.2 \%$, leaking $12.4 \%$, and infiltration $7.4 \%$ with a striking conclusion that when PIVC catheters were restarted, the risk of phlebitis is increased by 4.4 times. ${ }^{5}$ In addition, peripheral intravenous (IV) phlebitis has been found to be directly related to the medication or infusate that the patient received via peripheral access, ${ }^{6,7}$ and to the duration of dwell time. ${ }^{6}$

Previous studies investigated PIVC complications mainly in pediatrics, ${ }^{8,9}$ which is reported as a nurse-sensitive quality indicator in hospitals worldwide. ${ }^{10}$ However, we could not find any published studies tackling PIVC complications among adults in the Saudi population. Thus, the aim of this study was to determine the pattern and incidence of PIVC complications among patients admitted to a tertiary health care facility in the Kingdom of Saudi Arabia. This was achieved through the following objectives: 1) estimation of the cumulative incidence (CI) and density incidence (DI) for major PIVC complications, 2) identification of significant risk factors for PIVC complications such as patient-related characteristics or catheter-related characteristics, and 3) determination of the timeline for the occurrence of various PIVC complications.

\section{Study design}

This is a prospective cohort study, in which the incidence of PIVCs phlebitis and other complications was assessed periodically on 12-hour intervals up to 96 hours after insertion.

\section{Study area/setting}

King Abdulaziz Medical City (KAMC), Riyadh, Saudi Arabia, was established in May 1983. Since then, it has continued to expand, while providing services for a rapidly growing patient population in all of its catchment areas. Since its inauguration in February 2001, and within a short period, $\mathrm{KAMC}$ has been recognized as a distinguished health care provider with bed capacity of 690 beds.

\section{Study subjects and sampling technique}

Fourteen sub-settings were selected with a total bed capacity of 250 beds, categorized into four main groups based on the level of care provided: emergency (observation, adult, and critical), critical (neurological, surgical, intermediate, medical intensive care), cardiac (preoperative, postoperative, general), and general (four medicine/surgery wards). Adult patients admitted to the selected units at KAMC during November 2012 and January 2013 were screened through a number of inclusion/exclusion criteria. Recruited patients were adults ( $\geq 18$ ) who underwent PIVC insertions during the time of study, and agreed to participate in the study and signed the informed consent. Patients with preexisting skin breakdowns at insertion sites (rashes, lacerations, and trauma) and immune-compromised health conditions and those with previously inserted PIVCs from outside KAMC were all excluded. A total of 359 patients constituted the target of this study.

\section{Data collection}

In-service education regarding the study and the ethical rights of participants through a competency workshop was provided to a team of infection prevention and control practitioners to familiarize them with the principles of PIVCs insertion and its possible subsequent complications. Visual aids and power point illustrations of PIVC complications were utilized for training.

\section{Data collection tool}

PIVCs insertion technique at KAMC is standardized based on the hospital policy and infection control manual for procedures. Although the $2011 \mathrm{CDC}$ guidelines ${ }^{11}$ recommend changing and replacing PIVCs after 72-96 hours, to reduce both the risk for infection and patient discomfort associated with phlebitis, KAMC nurses adopt the 72-hour change whether clinically indicated or not. A data collection sheet was used to collect data on the following characteristics:

A. Patient-related characteristics: medical record number, patient initials, age groups, sex, comorbidities, such as diabetes, renal problems, liver dysfunctions, surgery, and others.

B. PIVCs-related characteristics: size of catheter, type of dressing (transparent or gauze), site of insertion (upper arm, cubital fossa, forearm, wrist, hand), and nature of PIVC infusate (hydration [0.09\%/0.45\% NaCl, Dextro/ $\mathrm{NaCl}$, etc], antibiotics, hyperglycemic solutions [D30 water], blood products, electrolytes, others).

C. Outcome characteristics: The Visual Inspection Phlebitis (VIP) scale from the third edition of the standards for infusion therapy ${ }^{12}$ is an internationally adopted tool that has been tested in literature and used in clinical settings worldwide. Phlebitis was defined as the presence of two 
or more signs of pain, tenderness, warmth, erythema, swelling, or a palpable cord, ${ }^{8,13}$ with or without purulent drainage from the catheter insertion site. ${ }^{14}$ The VIP scale can range from 0 , indicating no symptoms of phlebitis, to 5 , with signs of purulent drainage, redness, and a palpable cord greater than 3 inches. ${ }^{14}$ Infiltration was defined as permeation of IV fluid into the interstitial compartment, causing swelling of the tissue around the site of the catheter.

All PIVCs were changed for a score of 2 or more, determined by the presence of a cold or warm skin region around the insertion site, pain, redness, and/or edema extending from 1 inch to $\geq 2$ inches the PIVC site. ${ }^{15}$

Members of the data collection team assessed the PIVC site every 12 hours. A phlebitis score was assigned and recorded for each PIVC site. If the PIVC needed to be removed for any reason, including completion of treatment or discharge, the reason for and time of removal were documented. Patients were not followed up after discharge. Data regarding the number of failed PIVC attempts per patient were not recorded as the nurses were not under study investigation. Dressings were changed as necessary according to hospital policy.

\section{Ethical issues}

Data collectors were trained on how to approach the study participants and explain the dimensions of the study. Patients who were conscious and oriented to consent were enrolled after signing written consents whereas unconscious, disoriented, or intubated patients were enrolled after gaining consent from their families or legal guardians. There was neither a usage of experimental items nor a testing of a new product. Patient privacy and confidentiality of data were secured. This study was approved by the IRB of the Ministry of National Guard, Riyadh, Saudi Arabia (April 4, 2012, RR 11/069).

\section{Data management and analysis}

SPSS statistical software (Version 19, SPSS Inc, Chicago, IL, USA) was used for data entry and analysis. Pearson $\chi^{2}$ test and $\chi^{2}$ test for linear trend were used for categorical data. The relative risks (RRs) and 95\% confidence intervals were calculated for the proportion of patients with complicated catheters and for the individual factors that made up the composite measures. CI was calculated by dividing the total number of complicated catheters over the total number of catheters multiplied by 100 . DI for each group was calculated by dividing the total number of complicated catheters over the total number of days catheterized, multiplied by 1,000. To predict the significant predictors of PIVCs complications, logistic regression analyses were applied. Significance was considered at $P$-value $<0.05$.

\section{Results \\ Patient characteristics}

Eight hundred and forty-two PIVC sites from 359 patients (204 males and 155 females) were followed up during a total of 2,505 catheter days. One half of all patients were 65 years and above, $77(21.4 \%)$ aged between 18 years and 45 years, and 102 (28.4\%) aged between 46 years and 64 years, with no significant sex difference. The majority of patients, 276 (76.9\%), had medical, chief admission complaints, whereas surgical/trauma cases were $46(12.8 \%)$, and infectious $37(10.3 \%)$.

\section{Catheter-related characteristics}

Transparent dressing was applied for the majority of catheter sites, 697 (82.8\%), while gauze dressings were used for $145(17.2 \%)$. Catheter sizes G20 and G22 were mainly inserted by nurses, 318 (37.8\%) and 308 (36.6\%), respectively, followed by G18, 192 (22.8\%), with significant sex difference $(P=0.021)$. PIVCs were frequently inserted in hands, $263(31.2 \%)$, wrists $250(29.7 \%)$, and lower arms $242(28.7 \%)$, with only $79(9.4 \%)$ in cubital fossi, and less than $1 \%$ in upper arms. Hands ranked first as a site of insertion for females $126(36.0 \%)$, while lower arm ranked first among males $154(31.3 \%), P=0.024$. Hydration was the most frequent infusate, $387(46.0 \%)$, followed by antibiotics, 241 (28.6\%), while blood products and electrolytes constituted $107(12.7 \%)$ and $45(5.3 \%)$ of all infusates, respectively, with no significant sex difference $(P=0.257)$. More than one half of insertions were done by senior staff nurses, 489 (58.1\%), and 325 (38.6\%) were inserted by junior staff nurses ( $<2$ years experience), while IV skilled team contributed in only $28(3.3 \%)$ of all insertions, with no significant sex difference.

\section{Incidence of PIVC-related complications}

Complicated catheters were found in 141 (39.3\%) recruited patients, with a total number of 273 non-mutually exclusive various types of complications (32.4/100 catheters). The total number of complicated catheters was 190 catheters resulting in a CI of 22.56/100 catheters, and a DI of 75.84/1,000 catheter days (Figure 1). Phlebitis ranked first among complications, with a CI of $148(17.6 \%)$, followed by pain, 64 (7.6\%), leaking, 33 (3.9\%) and dislodgement, 20 (2.4\%), 


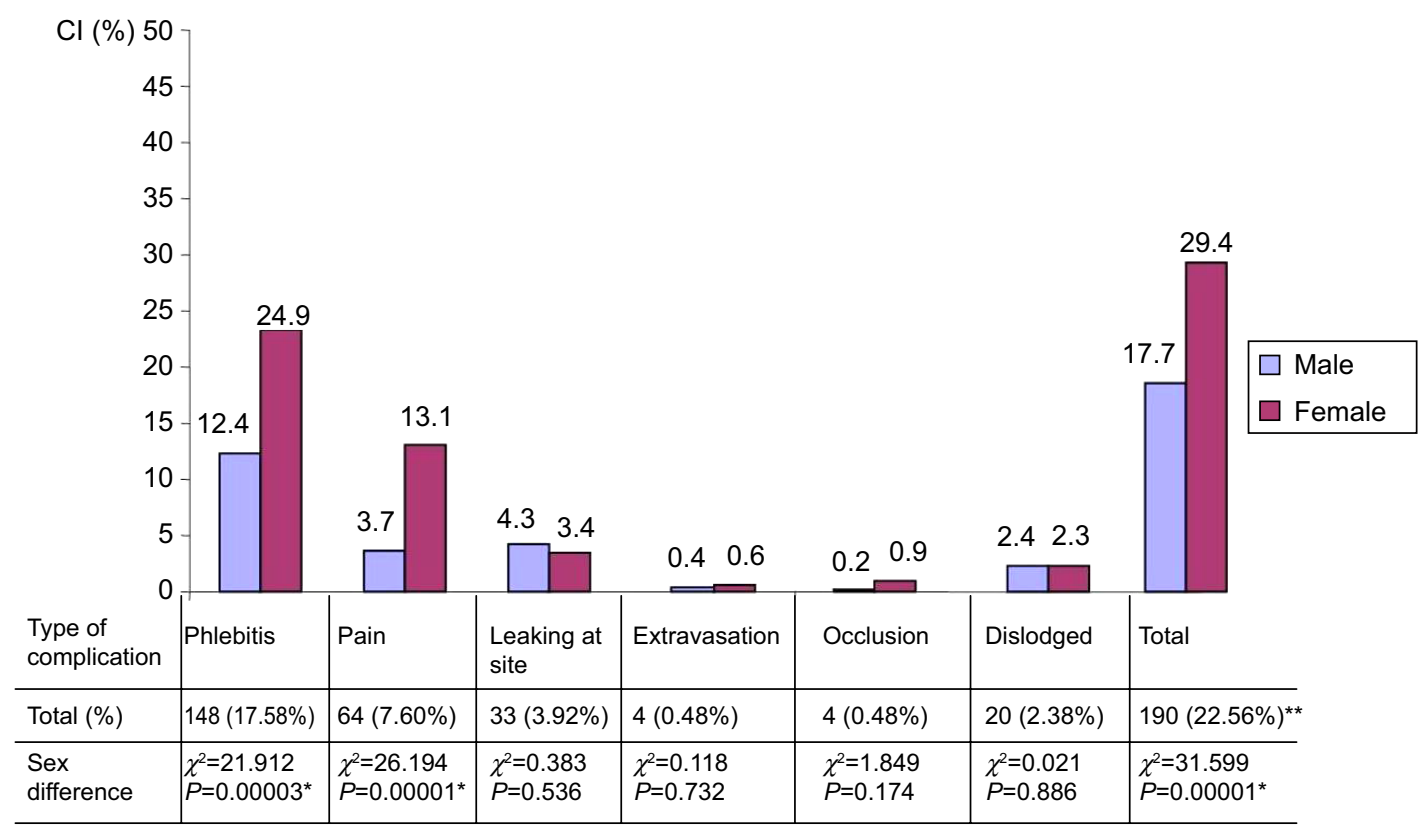

Figure I Cumulative incidence of peripheral intravenous catheter complications by sex.

Notes: *Sex difference is statistically significant. **Complications by catheters are non-mutually exclusive.

Abbreviation: $\mathrm{Cl}$, cumulative incidence.

and extravasations and occlusion, four $(0.5 \%)$ each. Females showed significantly higher CI of complications than males, $103(29.4 \%)$ vs $87(17.7 \%), P=0.00001$. This difference was evident for both phlebitis $(P<0.0001)$ and pain $(P<0.001)$. The onset time of PIVC complications ranged from 30.7 hours (for dislodgement) to 52.64 hours (for leaking). Second day after insertion was the encounter of all complications (Figure 2).

Female patients were 1.66 times more likely to encounter complications as compared to males $(\mathrm{RR}=1.66,95 \%$ confidence interval: $1.29-2.13, P=0.000059)$. Patients on IV medication were 1.41 times more likely to contract complications than those on hydration $(\mathrm{RR}=1.41,95 \%$ confidence

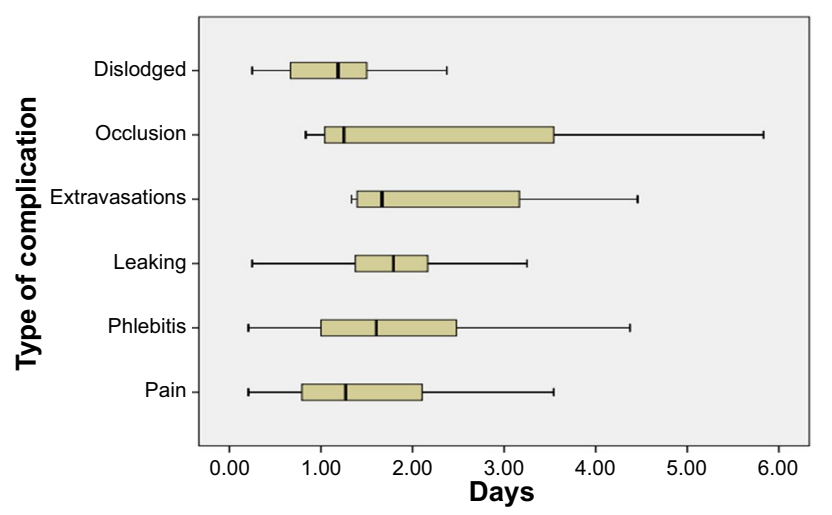

Figure 2 Average time of onset of various peripheral intravenous catheter complications in days. interval: $1.10-1.82, P=0.006)$. Meanwhile, patients with small-sized catheters were about two times more likely to contract complications than those with large-sized catheters ( $\mathrm{RR}=1.84,95 \%$ confidence interval: $1.44-2.36, P=0.000001)$ (Table 1).

Based on catheter complications per 1,000 device days, DI of complications was significantly higher among females than males ( 101.57 vs $58.35 / 1,000$ catheter days, $z=3.856$, $P=0.000115$ ) (Table 1). Females were 1.74 times more likely to contract PIVC-related complications than males $(\mathrm{RR}=1.74$, 95\% confidence interval: $1.30-2.31, P=0.000115)$. However, after adjusting for all these possible confounders, phlebitis was predicted with female sex $(P<0.001)$, insertion in fore/ upper $\operatorname{arm}(P=0.024)$, and infusion of medication $(P=0.02)$. Removal time for PIVCs insertion was not a significant predictor of phlebitis ( $R R=1.46, P=0.08)$ (Table 2). Table 3 shows a summary of the results of the study.

Figure 3 shows a significant dose-response relationship between the number of PIVCs inserted per individual patient and the proportion of patients who contracted one or more complications $\left(\chi^{2}=20.30, P<0.00001\right)$. This proportion changed from $22.39 \%$ with one insertion to $50 \%$ with three insertions and $100 \%$ with seven insertions.

\section{Discussion}

Although IV therapy is one of the most commonly performed procedures in hospitalized patients, it remains 
Table I Cumulative incidence and density incidence of PIVC-related complications by patient and catheter characteristics

\begin{tabular}{|c|c|c|c|c|c|c|}
\hline & \multicolumn{3}{|c|}{ Cumulative incidence } & \multicolumn{3}{|l|}{ Density incidence } \\
\hline & $\begin{array}{l}\text { Complicated } \\
\text { catheter per } \\
\text { 1 } 00 \text { catheters, } \\
190 / 842(22.56)\end{array}$ & $\begin{array}{l}\text { 95\% Cl, } \\
|9.87-25.5|\end{array}$ & $\begin{array}{l}\text { Risk ratio } \\
(95 \% \mathrm{CI})\end{array}$ & $\begin{array}{l}\text { Complicated } \\
\text { catheter per I,000 } \\
\text { PIVC days, 190/ } \\
2,505(75.84)\end{array}$ & $\begin{array}{l}95 \% \mathrm{Cl}, \\
66.10-86.80\end{array}$ & $\begin{array}{l}\text { Risk ratio } \\
(95 \% \mathrm{CI})\end{array}$ \\
\hline \multicolumn{7}{|c|}{ Patient characteristics } \\
\hline \multicolumn{7}{|c|}{ Sex } \\
\hline Male & $87 / 492(17.68)$ & $|4.56-2| .30$ & I & $87 / I, 49 \mid(58.35)$ & $47.60-71.50$ & I \\
\hline \multirow[t]{2}{*}{ Female } & $103 / 350(29.42)$ & $24.90-34.41$ & $\begin{array}{l}1.66 \\
(1.29-2.13)\end{array}$ & $103 / 1,014(101.57)$ & $84.50-121.70$ & $\begin{array}{l}1.74 \\
(1.30-2.31)\end{array}$ \\
\hline & \multicolumn{3}{|c|}{$\chi^{2}=16.147, P=0.000059 *$} & \multicolumn{3}{|c|}{$z$ score $=3.856, P=0.000115^{*}$} \\
\hline \multicolumn{7}{|c|}{ 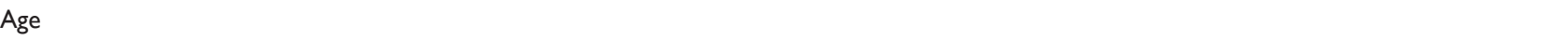 } \\
\hline $18-45$ & $31 / 170(18.23)$ & 13.16-24.73 & I & $3 \mathrm{I} / 5 \mathrm{I} 2(60.54)$ & $42.90-84.60$ & 1 \\
\hline \multirow[t]{2}{*}{$\geq 46$} & $159 / 672(23.66)$ & $20.60-27.02$ & $\begin{array}{l}1.29 \\
(0.91-1.83)\end{array}$ & I59/I,993 (79.77) & $68.70-92.50$ & $\begin{array}{l}1.31 \\
(0.89-1.93)\end{array}$ \\
\hline & \multicolumn{3}{|c|}{$\chi^{2}=2.286, P=0.1306$} & \multicolumn{3}{|c|}{$z$ score $=1.409, P=0.1587$} \\
\hline \multicolumn{7}{|l|}{ Chief complaints } \\
\hline Medical/infectious & 167/735 (22.72) & $19.84-25.89$ & $\begin{array}{l}1.05 \\
(0.7 \mid-1.55)\end{array}$ & 167/2, I79 (76.64) & $66.20-88.50$ & $\begin{array}{l}1.08 \\
(0.70-1.68)\end{array}$ \\
\hline Trauma/surgery & $\begin{array}{l}23 / 107(2 \mid .49) \\
\chi^{2}=0.080, P=0.77\end{array}$ & $|4.38-30.7|$ & 1 & $\begin{array}{l}23 / 326(70.55) \\
z \text { score }=0.3723, P=0 .\end{array}$ & $47.50-103.70$ & I \\
\hline \multicolumn{7}{|c|}{ Catheter characteristics } \\
\hline \multicolumn{7}{|c|}{ PIVC dressing } \\
\hline Gauze & $33 / 145$ (22.76) & 16.69-30.24 & $\begin{array}{l}1.01 \\
(0.72-1.40)\end{array}$ & $33 / 450(73.33)$ & $52.70-101.20$ & I \\
\hline \multirow[t]{2}{*}{ Transparent } & I57/697 (22.53) & $19.58-25.78$ & 1 & I57/2,055 (76.39) & $65.70-88.70$ & $\begin{array}{l}I .04 \\
(0.7|-| .5 I)\end{array}$ \\
\hline & $\chi^{2}=0.004, P=0.95$ & & & $z$ score $=0.2139, P=0.8$ & & \\
\hline \multicolumn{7}{|l|}{ Catheter size } \\
\hline Small (G22-G24) & $74 / 216(34.26)$ & $28.26-40.81$ & $\begin{array}{l}1.84 \\
(1.44-2.36)\end{array}$ & $74 / 950$ (77.90) & $62.50-96.70$ & $\begin{array}{l}1.04 \\
(0.78-1.39)\end{array}$ \\
\hline \multirow[t]{2}{*}{ Large (GI6-G20) } & $116 / 626(18.53)$ & $15.68-2 \mid .76$ & 1 & II 6/I,555 (74.60) & $62.60-88.70$ & I \\
\hline & $\chi^{2}=22.74, P=0.00$ & & & $z$ score $=0.290, P=0.77$ & & \\
\hline \multicolumn{7}{|l|}{ Care provider } \\
\hline Junior staff & $73 / 325$ (22.47) & $18.26-27.30$ & 1 & 73/975 (74.87) & $60.00-93.10$ & I \\
\hline \multirow[t]{2}{*}{ Senior staff } & $117 / 517$ (22.63) & $19.23-26.43$ & $\begin{array}{l}1.01 \\
(0.77-1.30)\end{array}$ & II $17 / 1,530(76.50)$ & $64.20-90.90$ & $\begin{array}{l}1.02 \\
(0.76-1.36)\end{array}$ \\
\hline & $\chi^{2}=0.003, P=0.95$ & & & $z$ score $=0.1417, P=0.8$ & & \\
\hline \multicolumn{7}{|l|}{ Insertion site } \\
\hline Hand-wrist & $109 / 5 \mid 3(21.25)$ & $17.93-25.00$ & I & 109/I,495 (72.90) & $60.80-87.20$ & 1 \\
\hline \multirow[t]{2}{*}{ Fore/upper arm } & $81 / 329(24.62)$ & $20.28-29.55$ & $\begin{array}{l}1.15 \\
(0.90-1.49)\end{array}$ & $81 / 1,010(80.19)$ & $65.00-98.60$ & $\begin{array}{l}1.10 \\
(0.82-1.46)\end{array}$ \\
\hline & $\chi^{2}=1.305, P=0.25$ & & & $\begin{array}{l}z \text { score }=0.6497 \\
P=0.5159\end{array}$ & & \\
\hline \multicolumn{7}{|l|}{ Infusate type } \\
\hline Hydration & $83 / 44 \mid$ (I8.82) & $15.45-22.73$ & 1 & $83 / 1,262(65.80)$ & $53.40-80.80$ & I \\
\hline Medication & I07/40| (26.68) & $22.59-31.22$ & $\begin{array}{l}1.41 \\
(1.10-1.82)\end{array}$ & $107 / 1,243(86.10)$ & $71.80-103.00$ & $\begin{array}{l}1.30 \\
(0.98-1.74)\end{array}$ \\
\hline & $\chi^{2}=7.43, P=0.006$ & & & $z$ score $=1.846, P=0.06$ & & \\
\hline Removal time** & & & & & & \\
\hline 72-96 hours & $46 / 238$ (19.33) & |4.82-24.82 & I & $46 / 817(56.3)$ & $42.50-74.30$ & $\begin{array}{l}1.46 \\
(0.94-2.27)\end{array}$ \\
\hline$>96$ hours & $36 / 182(19.78)$ & $14.64-26.17$ & $\begin{array}{l}1.02 \\
(0.69-\mid .5 I)\end{array}$ & $36 / 939(38.3)$ & $27.80-52.60$ & I \\
\hline & $\chi^{2}=0.0134, P=0.9$ & & & z score $=1.738, P=0.08$ & & \\
\hline
\end{tabular}

Notes: $* P$-value significant at $<0.05$. $* *$ Mutually exclusive.

Abbreviations: $\mathrm{Cl}$, confidence interval; PIVC, peripheral intravenous catheter. 
Table 2 Logistics regression for all possible predictors for PIVC complications

\begin{tabular}{|c|c|c|c|c|c|c|c|c|c|c|c|c|}
\hline & \multicolumn{4}{|c|}{ Overall complications } & \multicolumn{4}{|c|}{ Phlebitis } & \multicolumn{4}{|c|}{ Other complications } \\
\hline & $\beta$ & SE & $\begin{array}{l}\text { Adj } \\
P \text {-value }\end{array}$ & $\begin{array}{l}\text { Adj RR } \\
\text { (95\% Cl) }\end{array}$ & $\beta$ & SE & $\begin{array}{l}\text { Adj } \\
P \text {-value }\end{array}$ & $\begin{array}{l}\text { Adj RR } \\
\text { (95\% Cl) }\end{array}$ & $\beta$ & SE & $\begin{array}{l}\text { Adj } \\
P \text {-value }\end{array}$ & $\begin{array}{l}\text { Adj RR } \\
(95 \% \mathrm{Cl})\end{array}$ \\
\hline \multicolumn{13}{|l|}{ Sex } \\
\hline (female vs male) & 0.666 & 0.171 & $0.000001 *$ & $\begin{array}{l}1.94 \\
(1.39-2.72)\end{array}$ & 0.892 & 0.190 & $0.000003^{*}$ & $\begin{array}{l}2.44 \\
(1.68-3.54)\end{array}$ & 0.738 & 0.207 & $0.0003 *$ & $\begin{array}{l}2.09 \\
(1.39-3.13)\end{array}$ \\
\hline \multicolumn{13}{|l|}{ Age } \\
\hline$(\geq 46$ vs $\mid 8-45)$ & 0.179 & 0.231 & 0.440 & $\begin{array}{l}1.19 \\
(0.76-1.88)\end{array}$ & 0.359 & 0.265 & 0.175 & $\begin{array}{l}1.43 \\
(0.85-2.40)\end{array}$ & -0.138 & 0.269 & 0.607 & $\begin{array}{l}0.87 \\
(0.5 I-1.47)\end{array}$ \\
\hline \multicolumn{13}{|l|}{ Chief complaints } \\
\hline $\begin{array}{l}\text { (trauma/surgery vs } \\
\text { medical/infectious) }\end{array}$ & -0.317 & 0.302 & 0.294 & $\begin{array}{l}0.72 \\
(0.40-|.3|)\end{array}$ & 0.038 & 0.316 & 0.905 & $\begin{array}{l}1.03 \\
(0.55-1.92)\end{array}$ & -0.951 & 0.448 & $0.034^{*}$ & $\begin{array}{l}0.38 \\
(0.16-0.92)\end{array}$ \\
\hline \multicolumn{13}{|l|}{ PIVC dressing } \\
\hline $\begin{array}{l}\text { (gauze vs } \\
\text { transparent) }\end{array}$ & 0.065 & 0.224 & 0.773 & $\begin{array}{l}1.06 \\
(0.68-1.65)\end{array}$ & -0.006 & 0.253 & 0.982 & $\begin{array}{l}0.99 \\
(0.60-1.63)\end{array}$ & -0.016 & 0.272 & 0.953 & $\begin{array}{l}0.98 \\
(0.57-1.67)\end{array}$ \\
\hline \multicolumn{13}{|l|}{ Catheter size } \\
\hline $\begin{array}{l}\text { (large: G16-G20 vs } \\
\text { small: G22-G24) }\end{array}$ & 0.012 & 0.177 & 0.946 & $\begin{array}{l}1.01 \\
(0.71-1.43)\end{array}$ & 0.189 & 0.198 & 0.340 & $\begin{array}{l}1.20 \\
(0.82-1.78)\end{array}$ & -0.047 & 0.213 & 0.825 & $\begin{array}{l}0.95 \\
(0.62-1.44)\end{array}$ \\
\hline \multicolumn{13}{|l|}{ Care provider } \\
\hline $\begin{array}{l}\text { (senior staff vs } \\
\text { junior staff) }\end{array}$ & 0.090 & 0.177 & 0.612 & $\begin{array}{l}1.09 \\
(0.77-1.54)\end{array}$ & -0.018 & 0.195 & 0.926 & $\begin{array}{l}0.98 \\
(0.67-1.43)\end{array}$ & 0.228 & 0.216 & 0.290 & $\begin{array}{l}1.25 \\
(0.82-1.91)\end{array}$ \\
\hline \multicolumn{13}{|l|}{ Insertion site } \\
\hline $\begin{array}{l}\text { (fore/upper arm vs } \\
\text { hand-wrist) }\end{array}$ & 0.286 & 0.173 & 0.098 & $\begin{array}{l}1.33 \\
(0.94-1.86)\end{array}$ & 0.427 & 0.189 & $0.024^{*}$ & $\begin{array}{l}1.53 \\
(1.05-2.22)\end{array}$ & 0.406 & 0.207 & $0.049^{*}$ & $\begin{array}{l}1.50 \\
(1.00-2.25)\end{array}$ \\
\hline \multicolumn{13}{|l|}{ Infusate type } \\
\hline $\begin{array}{l}\text { (medication vs } \\
\text { hydration) }\end{array}$ & 0.472 & 0.171 & $0.006 *$ & $\begin{array}{l}1.60 \\
(1.14-2.24)\end{array}$ & 0.438 & 0.189 & $0.02 *$ & $\begin{array}{l}1.55 \\
(1.07-2.24)\end{array}$ & 0.319 & 0.206 & 0.121 & $\begin{array}{l}1.37 \\
(0.91-2.05)\end{array}$ \\
\hline Constant & -2.080 & 0.308 & $<0.0001$ & 0.125 & -2.782 & 0.356 & $<0.0001$ & 0.06 & -2.429 & 0.364 & $<0.0001$ & 0.08 \\
\hline
\end{tabular}

Note: *Indicates statistically significant association.

Abbreviations: PIVC, peripheral intravenous catheter; $\beta$, coefficient of determination; SE, standard error; RR, relative risk; Cl, confidence interval; Adj, adjusted.

susceptible to infectious and noninfectious complications. ${ }^{2}$ Approximately $1 \%-10 \%$ of such patients develop local or systemic catheter-related infections caused by alteration or disruption of skin integrity which can be an open pathway for colonization of microorganisms. ${ }^{2,16}$ In the present study, $39.3 \%$ of patients with PIVCs showed one or more complication. The frequency of phlebitis varied from $1 \%$ to $79 \%$ in various observational studies. ${ }^{17}$ In the present study, our overall combined complicated catheter rates were 22.6/100 catheters. This rate is lower than the rate of $35 \%$ in a study conducted in a comparable patient population. ${ }^{4}$ However, the rate of phlebitis in this study was $17.6 \%$, exceeding the rates of $3 \%$ in the former study. ${ }^{4}$ Complications may be ascribed to a number of factors such as the size of the catheter, insertion site preparation, type of infusion, insertion technique, catheter dwell time, dressing type, and the insertion site. ${ }^{18-20}$ In the present study, PIVCs were inserted frequently in hands, wrist, and lower arm. Hands ranked first as a site of insertion for females, while lower arm ranked first among males. The dorsum of the hand and forearm insertion site, which should be primarily selected according to the national and local guidelines on medical wards, were utilized frequently

Table 3 Summary of study results

\begin{tabular}{ll}
\hline Number of patients & 359 \\
Number of PIVCs & 842 \\
Total catheter duration (days) & 2,505 \\
Number (\%) of complications & $273 / 842(32.42 / 100$ catheters) \\
Number (\%) of patients with complications & $141 / 359(39.3 \%)$ \\
Number of complicated catheters & 190 \\
Cumulative incidence (\%) & $190 / 842(22.56$ catheters/I00 catheters, $95 \%$ Cl: I9.87-25.5I) \\
Density incidence (per I,000 catheter days) & $190 / 2,505(75.84$ catheters/I,000 catheter days, $95 \%$ Cl: $66.10-86.80)$ \\
Average number of catheters/patients & $1.00 \pm 1.45$
\end{tabular}

Abbreviations: PIVCs, peripheral intravenous catheters; $\mathrm{Cl}$, confidence interval. 


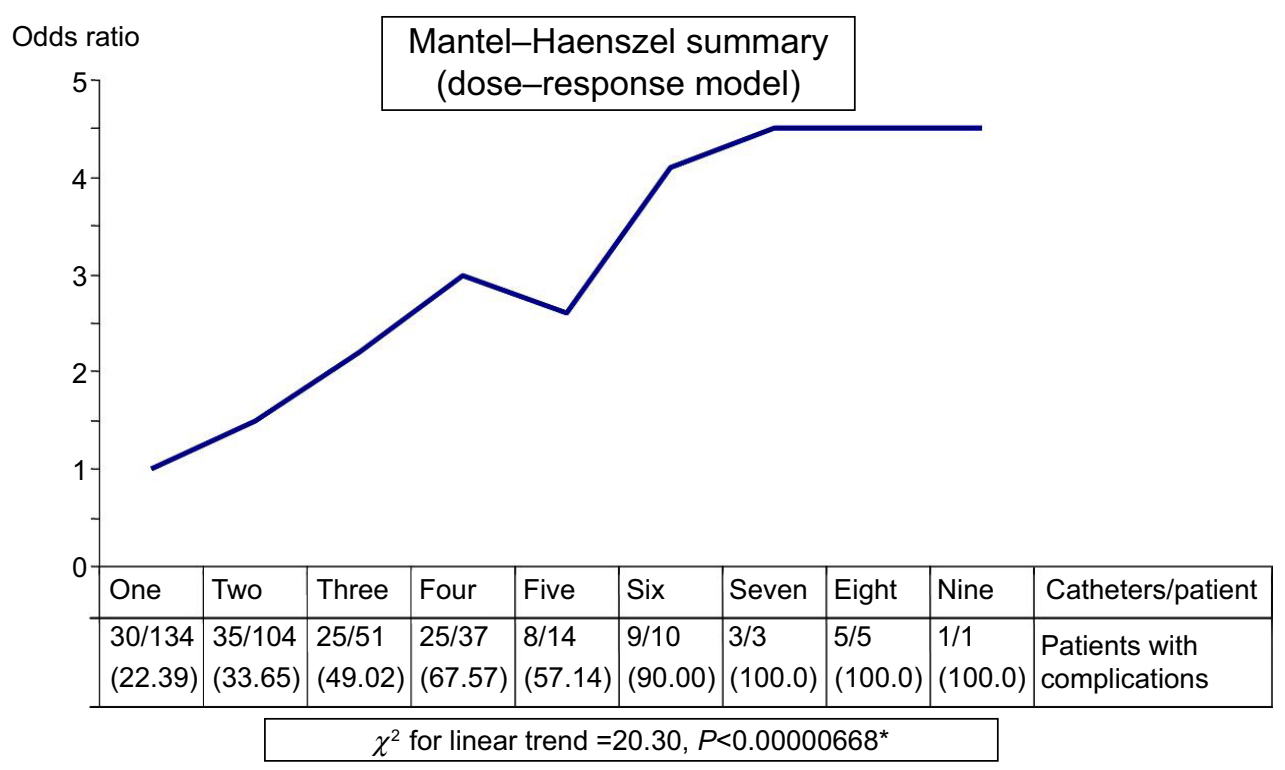

Figure 3 Relationship between the frequency of insertions per individual patient and incidence of complications. Note: Numbers in parentheses represent percentages and *indicates significant positive dose-response relationship.

in a previous study. ${ }^{2}$ The antecubital region was more commonly used than the dorsum of the hand. ${ }^{4}$ Insertion in fore/ upper arm was a significant predictor of both phlebitis and other complications in our study.

The use of an appropriate type of dressing is intended to keep the insertion site clean and dry while also preventing external contamination and trauma. ${ }^{2,18}$ In the present study, transparent dressing was done for the majority of catheter sites. There are reports that dressing regimens and methods of securing catheters may contribute to the occurrence of infection contributing to complications including infiltration, extravasation, and catheter displacement. ${ }^{2}$ However, in the present study, incidence of complications was not significantly associated with the type of dressing. This finding was in agreement with the conclusion of a systematic review and meta-analysis that demonstrated the absence of any relationship between the type of dressing used in PIVC insertion sites and the occurrence of phlebitis, infiltration, or skin dwelling bacteria in adult patients. ${ }^{21}$ However, a previous study concluded that dressing with sterile gauze maintained the catheter in place for a longer time. ${ }^{21}$ The use of smaller caliber catheters is related to reducing the occurrence of phlebitis, since they prevent mechanical irritation to the interior walls of small-diameter veins. ${ }^{5,18}$ In the present study, G20 and G22 were the main catheter sizes used (37.8\% and $36.6 \%$, respectively), followed by G18 (22.8\%), with significant sex difference $(P=0.021)$. Patients with small-sized catheters were about two times more likely to contract complications than those with large-sized catheters.
However, after adjusting for other potential confounders, this association disappeared.

No studies in the literature review discussed the phlebitis rates and risks when toxic medications were infused using a peripheral catheter. ${ }^{5}$ In the present study, hydration was the most frequent infusate, followed by antibiotics medication infusion, that was a significant predictor of phlebitis and overall complications. Patients on IV medications were 1.41 times more likely to contract complications than those on hydration. These medications were mainly antibiotics, and higher complications might be attributed to some antibiotics' low $\mathrm{pH}$ levels, which are likely to increase the incidence of these complications. ${ }^{22}$

The patients' characteristics and condition are also risk factors for phlebitis ${ }^{23,24}$ that should be considered in an individual's care. ${ }^{2}$ In the present study, female patients were 1.66 times more likely to contract complications as compared to males, and DI of complications was significantly higher among females than males. Females were again 1.74 times more likely to contract PIVC-related complications than males. On the other hand, incidence was not significantly associated with age or the chief complaint. However, after adjusting for all possible confounders, female sex remained a significant predictor of higher incidence of overall complications and phlebitis, as well as other complications.

According to CDC guidelines, ${ }^{12}$ adult patient's catheters should be replaced within a 72-96-hour period in order to reduce complications. ${ }^{19}$ However, the findings of this study detected no difference between patients with PIVCs catheterized for 
$\leq 72$ hours and those catheterized for $\geq 96$ hours in terms of complication rates. This was in agreement with the notion that routine replacement of PIVCs has no effect on the incidence of catheter failures. ${ }^{4,25}$ This will increase the confidence in changing IV lines according to clinical signs and symptoms, rather than adopting predetermined time frames. ${ }^{11}$

Prior studies have found that the risk of phlebitis in PIVCs increases over the first 48 hours, but then decreases. 5,26,27 This finding was consistent with the findings of the present study, where the peak onset of all types of complications averaged at $44.33 \pm 32.41$ hours (95\% confidence interval: 40.46-48.19 hours) and at 47.32 \pm 33.61 hours (95\% confidence interval: $41.86-52.78$ hours) for phlebitis (Figure 2). This exerts a challenge as it conflicts with the CDC regulations, ${ }^{11}$ that stated a safe dwell time of 72-96 hours. Therefore, a safer approach would be close routine observation of PIVCs and a change when clinically indicated is more appropriate. This finding also supports the current Infusion Nurses Society recommendation to remove PIVCs based on clinical indication rather than standard interval. ${ }^{28-30}$

The combined factors of multiple PIVC insertions and extended hospital stay place chronic patients, especially, at a higher risk for phlebitis and subsequently infection. ${ }^{1}$ This is consistent with the findings of the present study, where there is a positive dose-response relationship between multiple PIVC insertions per individual patient and the risk of contracting complications. Patients enduring a predictable extended length of stay of more than 1 week may be excellent candidates for better venous alternatives such as peripherally inserted central lines with longer dwell times, thus reducing the need for frequent PIVC insertions and subsequent catheter complications.

\section{Limitations}

Limitations of this study include the fact that it is based on patients recruited from a single setting. Not all potential subjects were recruited due to the lack of available research staff for recruitment. While data were collected across 2 months, we could not ensure that participants are representative of all patients through the whole year. Certain illnesses with seasonal variation may have been overrepresented in our sample. We were unable to adjust for the severity of illness or comorbid illnesses, yet the reason for admission was adjusted for. These factors could impact the wider generalizability of this study. Moreover, signs of phlebitis were measured when the PIVCs were in situ. Consequently, its occurrence after removal of the PIVCs was not recorded. Because phlebitis can arise after removal of PIVCs, ${ }^{5}$ phlebitis frequency might have been higher than reported. ${ }^{2}$

\section{Conclusion}

Incidence of PIVC-induced complications in this study was significantly higher than many rates found in literature. These complications were significantly predicted by sex (female), infusion of IV medication, and insertion sites (upper and forearm). Better insertion techniques may be sought to lower the incidences of PIVC complications to further delay their onset. It is suggested that health professionals seek PIVC insertion sites in the lower areas of the arm with emphasis on early shifting of medication administration from IV route to a safer oral route. Changing catheters is recommended when clinically indicated rather than routinely post-72 hours of insertion which in return minimizes the frequency of insertions per patient and subsequent complications.

\section{Acknowledgments}

This study was initiated and funded by King Abdullah International Medical Research Center, King Saud bin-Abdulaziz University for Health Sciences, Riyadh, Saudi Arabia. The authors would like to thank the Infection Prevention and Control Department and Nursing Services at KAMC, Ministry of National Guard Health Affairs, Saudi Arabia. Special thanks go to the infection control practitioners, Mr Elias Tannous, Mr Ahmed Azzam, Mr Bassem Abukhzam, Mr Joseph Tannous, Mr Kassem Zehri, Ms Nimfa Dagunton, Ms Marissa Alarcon, Ms Basema Shadfan, Ms Nahla Ragab, Ms Khawla Salman, Mr Ahmad Ibrahim, and Mr Tamer Abu Areeshi, for their contributions in data collection.

\section{Author contributions}

All authors contributed toward data analysis, drafting and revising the paper and agree to be accountable for all aspects of the work.

\section{Disclosure}

The authors declare that they have no competing interests.

\section{References}

1. Todd J. Peripherally inserted central catheters and their use in IV therapy. Br J Nurs. 1999;8(3):140-148.

2. Johansson ME, Pilhammar E, Khalaf A, Willman A. Registered nurses' adherence to clinical guidelines regarding peripheral venous catheters: a structured observational study. Worldviews Evid Based Nurs. 2008;5(3):148-159.

3. Maki DG, Kluger DM, Crnich CJ. The risk of bloodstream infection in adults with different intravascular devices: a systematic review of 200 published prospective studies. Mayo Clin Proc. 2006;81(9):1159-1171. 
4. Webster J, Clarke S, Paterson D, et al. Routine care of peripheral intravenous catheters versus clinically indicated replacement: randomised controlled trial. BMJ. 2008;337(7662):157-160.

5. Gallant P, Schultz AA. Evaluation of a visual infusion phlebitis scale for determining appropriate discontinuation of peripheral intravenous catheters. J Infusion Nurs. 2006;29(6):338-345.

6. Malach T, Jerassy Z, Rudensky B, et al. Prospective surveillance of phlebitis associated with peripheral intravenous catheters. Am J Infect Control. 2006;34(5):308-312.

7. Catney MR, Hillis S, Wakefield B, et al. Relationship between peripheral intravenous catheter dwell time and the development of phlebitis and infiltration. J Infusion Nurs. 2001;24(5):332-341.

8. US Renal Data System. Excerpts from the USRDS annual data report: atlas of end-stage renal disease in the United States: clinical indicators of care. Am J Kidney Dis. 2001;4(suppl 3):S79-S90.

9. Cornely OA, Bethe U, Pauls R, Waldschmidt D. Peripheral Teflon catheters: factors determining incidence of phlebitis and duration of cannulation. Infect Control Hosp Epidemiol. 2002;23(5):249-253.

10. American Nurses Association. ANA indicator history. Nursing World. Available from: http://www.nursingworld.org/MainMenuCategories/ ThePracticeofProfessionalNursing/PatientSafetyQuality/ResearchMeasurement/The-National-Database/Nursing-Sensitive-Indicators_1/ ANA-Indicator-History. Accessed June 8, 2014.

11. O'Grady NP, Alexander M, Dellinger EP, et al. Guidelines for the prevention of intravascular catheter-related infections. Clin Infect Dis. 2002;35(11):1281-1307.

12. The RCN IV Therapy Forum. Standards for Infusion Therapy. 3rd ed London: Royal College of Nursing; 2010:94s. [ISBN 978-1-906633-19-6]

13. Monreal M, Oller B, Rodriguez N, et al. Infusion phlebitis in postoperative patients: when and why. Pathophysiol Haemost Thromb. 2000;29(5):247-254.

14. Curran E, Coia J, Gilmour H, McNamee S, Hood J. Multi-centre research surveillance project to reduce infections/phlebitis associated with peripheral vascular catheters. J Hosp Infect. 2000;46(3):194-202.

15. Elliot TS. Intravascular-related sepsis-novel methods of prevention. Intensive Care Med. 2000;26:S45-S50.

16. Redelmeier DA, Livesley NJ. Adhesive tape and intravascular-catheterassociated infections. J Gen Intern Med. 1999;14(6):373-375.

17. Lanbeck P. Antibiotics and Infusion Phlebitis: Clinical and Experimental Studies [doctoral dissertation]. Malmö: Department of Infectious Diseases: Malmö University Hospital, Lund University; 2003.

18. Phillips LD. Complicações da terapia intravenosa. In: Phillips LD, editor. Manual de terapia intravenosa. Vol. 2. Porto Alegre: Artmed; 2001:236-298.
19. Centers for Disease Control and Prevention. Guidelines for the prevention of intravascular catheter-related infections. MMWR. 2002; 51(RR-10):1-36.

20. Callaghan S, Copnell B, Johnston L. Comparison of two methods of peripheral intravenous cannula securement in the pediatric setting. J Infusion Nurs. 2002;25(4):256-264.

21. Machado AF, Pedreira ML, Chaud MN. Prospective, randomized and controlled trial on the dwell time of peripheral intravenous catheters in children, according to three dressing regimens. Rev Lat Am Enfermagem. 2005;13(3):291-298.

22. Machado AF, Pedreira Mda L, Chaud MN. Adverse events related to the use of peripheral intravenous catheters in children according to dressing regimens. Rev Lat Am Enfermagem. 2008;16(3):362-367.

23. Tagalakis V, Kahn SR, Libman M, Blostein M. The epidemiology of peripheral vein infusion thrombophlebitis: a critical review. Am J Med. 2002;113(2):146-151.

24. Wallis MC, McGrail M, Webster J, et al. Risk factors for peripheral intravenous catheter failure: a multivariate analysis of data from a randomized controlled trial. Risk. 2014;35(1):63-68.

25. Webster J, Lloyd S, Hopkins T, Osborne S, Yaxley M. Developing a research base for intravenous peripheral cannula re-sites (DRIP trial). A randomised controlled trial of hospital in-patients. Int J Nurs Stud. 2007;44(5):664-671.

26. Grüne F, Schrappe M, Basten J, Wenchel H, Tual E, Stützer H. Phlebitis rate and time kinetics of short peripheral intravenous catheters. Infection. 2004;32(1):30-32.

27. Crnich CJ, Maki DG. The promise of novel technology for the prevention of intravascular device - related bloodstream infection. I. Pathogenesis and short-term devices. Clin Infect Dis. 2002;34(9):1232-1242.

28. Ascoli GB, DeGuzman PB, Rowlands A. Peripheral intravenous catheter complication rates between those indwelling $>96$ hours to those indwelling 72-96 hours: a retrospective correlational study. Int J Nurs. 2012;1(2):7-12.

29. Powell J, Tarnow KG, Perucca R. The relationship between peripheral intravenous catheter indwell time and the incidence of phlebitis. J Infusion Nurs. 2008;31(1):39-45.

30. Webster J, Osborne S, Rickard C, Hall J. Clinically-indicated replacement versus routine replacement of peripheral venous catheters Cochrane Database Syst Rev. 2010;3:CD007798.
Therapeutics and Clinical Risk Management

\section{Publish your work in this journal}

Therapeutics and Clinical Risk Management is an international, peerreviewed journal of clinical therapeutics and risk management, focusing on concise rapid reporting of clinical studies in all therapeutic areas, outcomes, safety, and programs for the effective, safe, and sustained use of medicines. This journal is indexed on PubMed Central, CAS,

\section{Dovepress}

EMBase, Scopus and the Elsevier Bibliographic databases. The manuscript management system is completely online and includes a very quick and fair peer-review system, which is all easy to use. Visit http://www.dovepress.com/testimonials.php to read real quotes from published authors. 